\title{
Effect of the Tube Bundle Configuration on the Experimental Two-Section Two-Zone Fluidized Bed Reactor Hydrodynamics
}

\author{
Ignacio Julián ${ }^{1}$, Fausto Gallucci ${ }^{2}$, Martin van Sint Annaland ${ }^{2}$, Javier Herguido ${ }^{1}$, \\ Miguel Menéndez ${ }^{1}$ \\ ${ }^{1}$ Catálisis, Separaciones moleculares e Ingeniería de Reactores (CREG) \\ Instituto de Investigación en Ingeniería de Aragón (I3A). \\ Universidad de Zaragoza, Mariano Esquillor s/n, 50018, Zaragoza, Spain. \\ Tel. +34-976762707, Fax +34-976762043, e-mail: ijulian@unizar.es \\ ${ }^{2}$ Eindhoven University of Technology (The Netherlands)
}

\begin{abstract}
Particle Image Velocimetry (PIV) and Digital Image Analysis (DIA) techniques have been used to study the effect of different tube bundle configurations on the hydrodynamic behaviour of a novel gas-solid catalytic reactor concept, the so called: Two-Section Two-Zone Fluidized Bed Reactor.
\end{abstract}

\section{Introduction}

The Two Zone Fluidized Bed Reactor (TZFBR) has been proposed as an attractive solution to perform gas-solid catalytic reactions where the catalyst suffers a rapid loss of activity due to coke deposition [1]. The singular configuration of the TZFBR provides 'in situ' catalyst regeneration. The use of two separated gaseous feeds (reactive and regenerative), fed at two different locations within a single fluidized bed reactor, generates two different atmospheres or reaction zones. The circulation of the catalyst particles between the two reactor zones as a result of the fluidization process allows the simultaneous catalytic reactions and catalyst regeneration. A recent modification to the TZFBR configuration provides different cross-sectional areas in each zone in order to achieve better fluid dynamic control. This allows low regenerative-toreactive flow rates when required [2]. The so-called Two-Section TZFBR (TS-TZFBR) includes a tapered bed region that connects the upper and lower reactor zones. Under certain fluidization conditions, the use of this novel reactor configuration may lead to slugging regimes within the narrower bed zone [3]. The eventual formation of slugs by bubble coalescence may hamper the axial solids recirculation and the gas-solid mass transfer, affecting the reactor performance. The use of internal elements, e.g. immersed tube bundle, in that bed region may help to overcome this limitation. In this study, six different horizontal tube bank configurations have been tested to evaluate the effect of the immersed tubes on the average bubble size and axial solids mass flow rates. Moreover, three gas velocity conditions and two different immersed distributor locations have been tested for each tube bundle configuration.

\section{Experimental Set up}

Experiments were performed in cold pseudo-2D TSTZFBR facilities with a tapered section angle $\alpha=$ $80^{\circ}$ with respect to the horizontal position. Noninvasive optical techniques, viz. Digital Image Analysis (DIA) and Particle Image Velocimetry (PIV), were used to determine bubble characteristics and solids circulation patterns. Fluidization recordings were performed with a LaVision ${ }^{\circledR}$ Imager Pro high speed camera and analyzed in $\mathrm{DaVis}$ 8.0.3, commercial software for image processing. The recording frequency was adjusted to $750 \mathrm{~Hz}$ to avoid image blurriness related to the fast solids movement and a time delay, $\Delta \mathrm{t}$, of $0.3 \mathrm{~ms}$ between two consecutive frames was selected for PIV processing. For each experimental condition, results have been averaged out from 2700 pairs of frames and 36 seconds of fluidization. In addition, two dimmable led lamps have been used to get homogeneous illumination on the front reactor wall and pressurized air was used as fluidization gas. Bed particles were non-spherical $\mathrm{SrAl}_{2} \mathrm{O}_{4}$ based phosphorescent solids, used as optical tracers in previous studies. Their size distribution, $\mathrm{d}_{\mathrm{p}}$, was in the range 200-320 $\mu \mathrm{m}$ with a bulk density, $\rho_{\mathrm{b}}=1.43$ $\mathrm{g} / \mathrm{cm}^{3}$ and a fixed bed porosity, $\varepsilon_{\text {packed }}$ of 0.58 . The minimum fluidization velocity of these particles, $\mathrm{u}_{\mathrm{mf}}$ $=10.1 \mathrm{~cm} / \mathrm{s}$, was determined by measuring the bed pressure drop at decreasing gas velocities in a straight vessel. Reactor dimensions are $65 \times 8 \times 0.8$ $\mathrm{cm}$ (height $\mathrm{x}$ max. width $\mathrm{x}$ depth). The maximum width corresponds to the upper bed zone width. The straight lower zone is $4 \mathrm{~cm}$ wide and $12 \mathrm{~cm}$ high. The tapered region between bed zones has an angle, $\alpha=80^{\circ}$ with respect to the horizontal position and connects the two straight bed zones. Experimental setup is shown in Figure 1. 


\section{Results}

A comparison of the PIV results obtained for different fluidization regimes and tube bank configurations (Figure 2) allowed the selection of a range of conditions, in which the solids circulation and the gas-solid mass transfer rates could be improved with respect to these in a conventional TS-TZFBR without internals. The use of staggered configurations is more effective to break gas bubbles (size reduction $>30 \%$ ) than the use of aligned tube banks. Hybrid configurations did not enhance the bubble shrinkage with respect to staggered ones but they resulted in sharper axial solid mass flow profiles, i.e. improved axial solids mixing within the region in which the tube bundle was located. It was concluded that the use of internal elements in the lower zone of a TS-TZFBR has a positive effect on the reactor performance, since it enhances breakage of big bubbles that could eventually lead to a short-circuit in the axial solids recirculation. In addition, the use of internal tubes did not increase solids circulation time dramatically and enhanced circulation paths (Figure 3).

\section{Conclusions}

Coupled PIV/DIA techniques allowed the hydrodynamic study of a pseudo-2D Two-Section Two-Zone Fluidized Bed Reactor using internals in its lower zone. The effect of different tube bank configurations on the reactor dynamics has been determined for a range of fluidization conditions. A

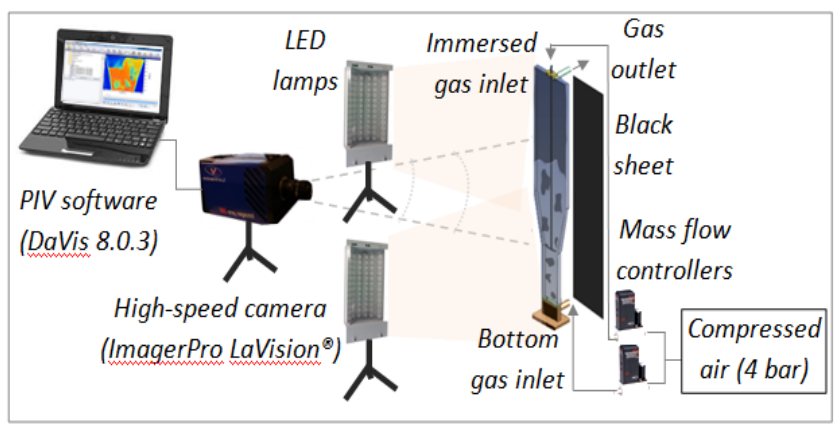

Figure 1. Experimental set-up scheme
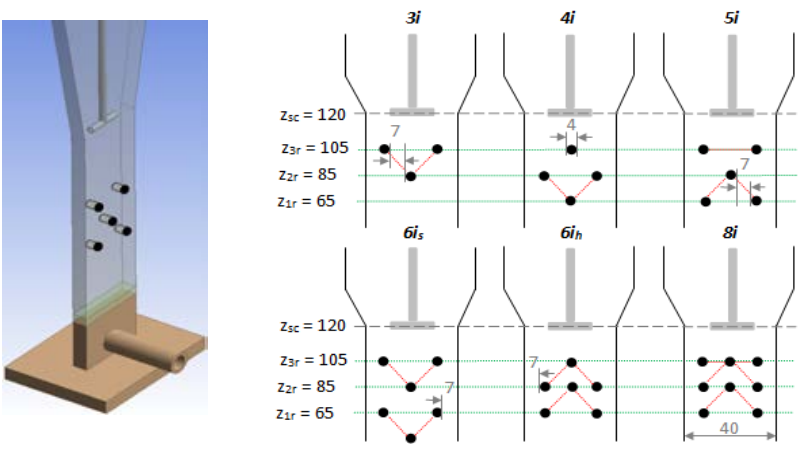

Figure 2. Examples of tested tube bundle configurations staggered configuration of 5 staggered-internals was able to reduce the average bubble size around 30\% within the upper region of the lower reactor zone, avoiding slugging regimes at usual TS-TZFBR fluidization flow rates. The use of internals slightly increased the solids circulation time. A DIA procedure was developed to quantify solid fluxes in upward and downward directions, respectively. This allowed the determination of average wake and emulsion solids fluxes along the bed. The axial profile of the upwards solids fluxes was compared to DIA bubbling size and velocity profiles resulting in high agreement.

\section{REFERENCES}

[1]. HERGUIDO, J., MENÉNDEZ, M. and SANTAMARÍA, J. On the use of fluidized bed catalytic reactors where reduction and oxidation zones are present simultaneously. Catalysis Today. 2005, 100(1-2), 181-189. Available from: doi:10.1016/j.cattod.2004.11.004.

[2]. JULIÁN, I., HERGUIDO, J., and MENÉNDEZ, M. A non-parametric bubble size correlation for a TwoSection Two-Zone Fluidized Bed Reactor (TSTZFBR). Powder Technology. 2014, 256(1), 146-157. Available from: doi:10.1016/j.powtec.2014.02.004.

[3]. JULIÁN, I., HERGUIDO, J., and MENÉNDEZ, M. Particle mixing in a Two-Section Two-Zone Fluidized Bed Reactor (TS-TZFBR). Experimental technique and Counter-Current Back-Mixing model validation. Industrial\&Engineering Chemistry Research, 2013, 52(38), 13587-13596. Available from: doi:10.1021/ie401334x.

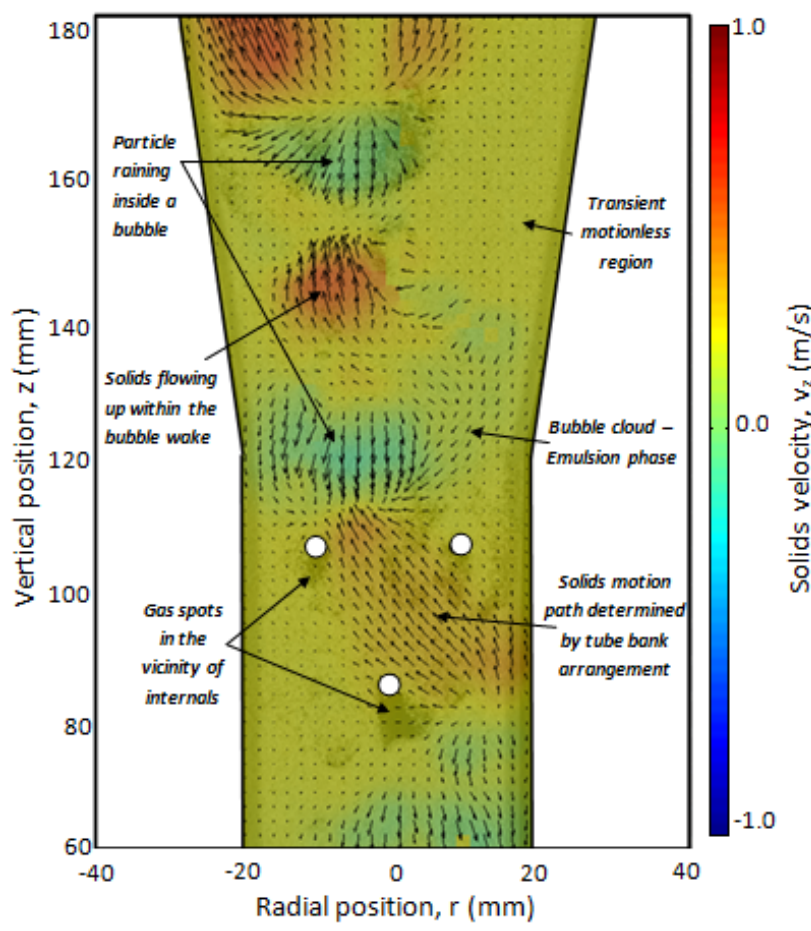

Figure 3. PIV result for a 3-staggered internals configuration 